\title{
Controlled Radical Polymerization of Captodative Substituted Methyl $\alpha$-Methoxyacrylate with Captodative Substituted Morpholino Succinonitrile
}

\author{
Hitoshi TanaKa, ${ }^{\dagger}$ Katsushi Aoki, Takahiro Hongo, and Yoshihiko Tezuka \\ Department of Optical Science and Technology, Faculty of Engineering, \\ Tokushima University, 2-1 Minamijosanjima, Tokushima 770-8506, Japan
}

(Received July 28, 1999)

\begin{abstract}
Radical polymerization of captodative (cd) substituted methyl $\alpha$-methoxyacrylate (MMOA) with cd substituted morpholino succinonitrile is studied kinetically at 90,110 , and $130^{\circ} \mathrm{C}$. The polymerization of MMOA proceeds at moderate rate to give a cd-capped dormant polymer in contrast to the polymerization with conventional azo initiator and the rate constant of the activation of the dormant is estimated to be intermediate between that of the nitroxide-mediated styrene polymerization and cd substituted succinonitrile initiated methyl methacrylate polymerization. On the basis of these results, the relationship between cd substitution effect and the stability of the dormants is discussed.
\end{abstract}

KEY WORDS Controlled Radical Polymerization / Captodative Substitution / Radical Initiator / Bimodal Size Exclusion Chromatogram / Morpholino Succinonitrile /

Molecular weight and polydispersity of a polymer depend much on the stability of both polymer and counter radicals dissociated from the dormant in a controlled radical polymerization. ${ }^{1,2}$ A lot of reagents have been developed in their polymerizations, and $2,2,6,6$,-tetramethylpiperdone-1-oxyl(TEMPO), ${ }^{3}$ halogen, ${ }^{4,5}$ cobalt chelate, ${ }^{6}$ phenylseleno, ${ }^{7}$ dithioester, ${ }^{8}$ and dithiocarbamate ${ }^{9}$ moieties are well-known such end-capping counter radicals.

Captodative (cd) substitution (geminal substitution of electron-accepting and -donating groups on the same atom) also brings about stabilization to a radical because of the electron push-pull resonance effect. Therefore, cd substitution has provided new types of monomers and initiators. ${ }^{10}$ Recently, we found that the cd substituted ethanes such as 1 initiate the radical polymerizations of styrene, methyl methacrylate (MMA), and vinyl acetate, and form a block copolymer through a homolysis of a dormant. ${ }^{11}$ Previous paper reported the rapid decomposition of 2 at moderate temperature and the molecular weight controlled radical polymerization of MMA initi-

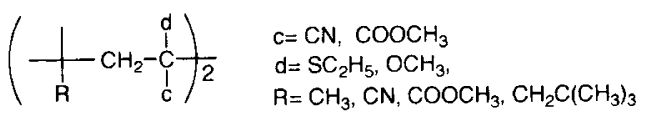

1
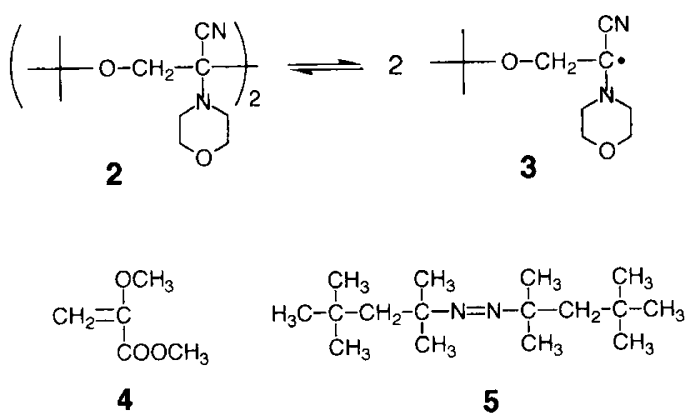

Scheme 1. ated and end-capped by radical $3 .^{12}$ The rate of the activation of the dormant capped by $\mathbf{3}$, however, was not high probably because of a positively larger reaction heat of the homolysis of the dormant due to the generation of the cd substituted persistent radical 3 and less persistent, i.e., transient, poly (MMA) radical. A higher rate of the activation of the dormant can be expected when both radicals generated by the homolysis are persistent or stable.

This paper deals with kinetic studies of the radical polymerization of cd substituted methyl $\alpha$-methoxyacrylate (MMOA) 4 with cd initiator (coupling product of cd substituted radicals) 2 in comparison with the polymerization with conventional azo initiator, i.e., $2,2^{\prime}$-azobis $(2,4,4$ trimethylpentane) 5 , and confirms cd effect on the controlled radical polymerization.

\section{EXPERIMENTAL}

\section{Materials}

2 was synthesized by the addition reaction of di- $t$ butyl peroxide $(2.68 \mathrm{~g}, 20 \mathrm{mmol})$ and $\alpha$-morpholino acrylonitrile ${ }^{13}(3.68 \mathrm{ml}, 20 \mathrm{mmol})$ in benzene under irradiation of high pressure mercury lamp at ambient temperature. Recrystallization of crude 2 from benzene gave $0.18 \mathrm{~g}$ of purified 2 (white needles) in a $4.2 \%$ yield ; $\mathrm{mp}$ $177^{\circ} \mathrm{C}$ (decomp.).

${ }^{1} \mathrm{H} \mathrm{NMR}\left(\mathrm{CDCl}_{3}\right): \delta 4.07\left(\mathrm{~s}, \mathrm{CH}_{2}, 4 \mathrm{H}\right), 3.74\left(\mathrm{t}, \mathrm{CH}_{2}, 8\right.$ $\mathrm{H}), 3.12\left(\mathrm{t}, \mathrm{CH}_{2}, 8 \mathrm{H}\right), 1.24 \mathrm{ppm}\left(\mathrm{s}, \mathrm{CH}_{3}, 18 \mathrm{H}\right)$. Anal. Calcd for $\mathrm{C}_{22} \mathrm{H}_{38} \mathrm{~N}_{4} \mathrm{O}_{4}: \mathrm{C}, 62.60 ; \mathrm{H}, 9.00 ; \mathrm{N}, 13.30$. Found : C, $62.54 ; \mathrm{H}, 8.90 ; \mathrm{N}, 13.12 \%$.

MMOA was prepared by reaction of methyl 2,3dibromopropionate and sodium methoxide according to the literature. ${ }^{14}$ Purification of MMOA was carried out by fractional distillation of the eluent from pyrolysis of the MMOA polymer at $270^{\circ} \mathrm{C}$ which was independently synthesized by the radical polymerization of crude MMOA ; yield : $91 \%$, bp $58-59^{\circ} \mathrm{C} / 13 \mathrm{mmHg}$. Commercial grade 5 (Wako Pure Chem.) was used without further purification.

\footnotetext{
${ }^{\dagger}$ To whom correspondence should be addressed.
} 


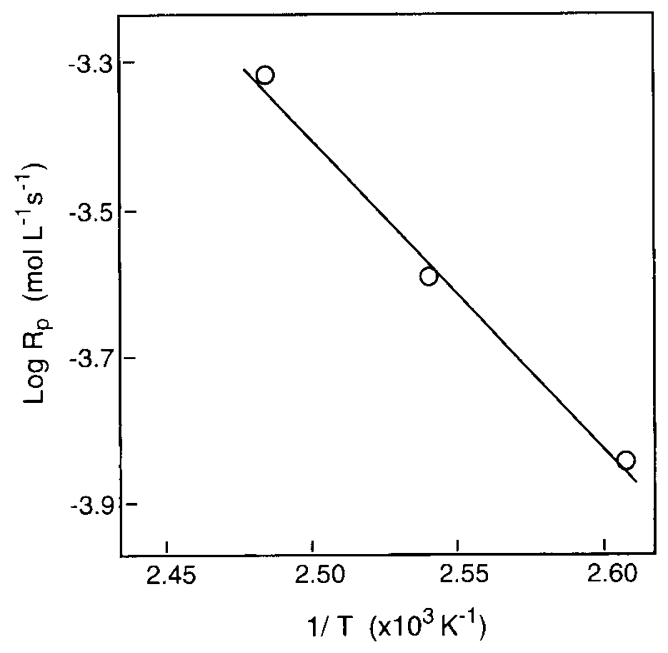

Figure 1. Dependence of overall polymerization rate $\left(R_{\mathrm{p}}\right)$ on temperature in the polymerization of MMOA with $\mathbf{5}$. $[\mathbf{5}]=5.0 \times 10^{-3}$ $\mathrm{mol} \mathrm{L}{ }^{-1}$.

\section{Polymerization}

Polymerizations were carried out in a sealed ampoule with shaking at given temperature. The ampoule which contained required amounts of reagents was degassed several times by a freeze-thaw method and then sealed under vacuum and placed in an oil bath kept at a constant temperature. The resulting polymer was isolated by pouring the contents of the ampoule into a large amount of diethylether.

\section{Measurements}

${ }^{1} \mathrm{H}$ NMR spectrum was measured on a JEOL JNM-MY $60(60 \mathrm{MHz})$ spectrometer using tetramethylsilane as internal standard. Number-and weight-average molecular weight $\left(M_{n}\right.$ and $\left.M_{w}\right)$ of the polymer was determined by SEC using a Tosoh HLC-8020 (columns : TSK gel-G7000 $\mathrm{HHR}+\mathrm{G} 5000 \mathrm{HHR}+\mathrm{G} 3000 \mathrm{HHR}$ ) in $0.1 \%$ tetrahydrofuran solution based on a standard polystyrene at $35^{\circ} \mathrm{C}$. Quantitative analysis in SEC for rate determination was performed using internal standard polystyrene with $M_{n}$ $=1.03 \times 10^{6}$ and $M_{w} / M_{n}=1.01$.

\section{RESULTS AND DISCUSSION}

\section{Polymerization with 5}

Polymerization of MMOA with $\mathbf{5}$ was carried out in bulk at 110,120 , and $130^{\circ} \mathrm{C}$, and the overall polymerization rate $\left(R_{\mathrm{p}}\right)$ was estimated. Figure 1 shows a plot of log $R_{\mathrm{p}}$ against the reciprocal of the absolute temperature (1/ $T$ ). From the slope of the plot, the activation energy of the overall polymerization $\left(E_{\mathrm{a}}\right)$ is calculated to be 80.3 $\mathrm{kJ} \mathrm{mol}^{-1}$ in the MMOA polymerization with $\mathbf{5}$. On the basis of the activation energy $\left(E_{\mathrm{d}}\right)$ of the decomposition of $5\left(E_{\mathrm{d}}=132.9 \mathrm{~kJ} \mathrm{~mol}{ }^{-1}\right),{ }^{15}$ the value of $E_{\mathrm{p}}-E_{\mathrm{t}} / 2$, in which $E_{\mathrm{p}}$ and $E_{\mathrm{t}}$ represent an activation energy of propagation and termination respectively, is calculated to be $13.9 \mathrm{~kJ} \mathrm{~mol}^{-1}$ assuming $E_{\mathrm{a}}=E_{\mathrm{d}} / 2+\left(E_{\mathrm{p}}-E_{\mathrm{t}} / 2\right)$ as is known in conventional radical polymerization. The value of $13.9 \mathrm{~kJ} \mathrm{~mol}^{-1}$ is smaller than that of the conventional monomers, ${ }^{15}$ but similar to that obtained by the radical polymerization of cd substituted methyl $\alpha$ acetoxyacrylate $\left(12.1 \mathrm{~kJ} \mathrm{~mol}^{-1}\right) .{ }^{16}$ Larger $E_{\mathrm{t}}$ may be re-

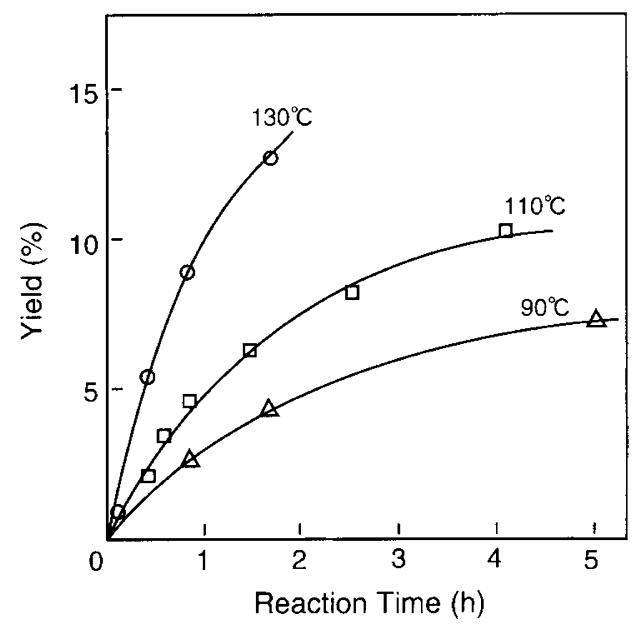

Figure 2. Time-polymer yield curves in the polymerization of MMOA with 2 at 130,110 , and $90^{\circ} \mathrm{C}$. $[2]=5.0 \times 10^{-3} \mathrm{~mol} \mathrm{~L}^{-1}$.

sponsible for such smaller $E_{\mathrm{p}}-E_{\mathrm{t}} / 2$ of MMOA as known for methyl $\alpha$-acetoxyacrylate although detailed analysis should be necessary.

\section{Polymerization with 2}

A variation of polymer yield with reaction time in the MMOA polymerization with 2 at 90,110 , and $130^{\circ} \mathrm{C}$ is dipicted in Figure 2. The polymerization proceeds without induction period and the yield increases with increasing temperature. In contrast to the polymerization of MMOA with azo initiator where the resulting poly (MMOA) represents a unimodal SEC curve and unchangeable polydispersity $\left(M_{w} / M_{n}=1.53-1.57\right)$, however, polymerization with 2 gives a polymer with bimodal SEC curve at 110 and $130^{\circ} \mathrm{C}$ or broadening one at 90 ${ }^{\circ} \mathrm{C}$ as clearly seen in Figure 3. Fractional analysis of SEC curves at 110 and $130^{\circ} \mathrm{C}$ gives yields of individual high and low molecular weight polymers, HM and LM polymers respectively. LM polymer formed by the polymerization of MMOA initiated by the primary radical $\mathbf{3}$ is gradually reduced, but the yield of the HM polymer increases with reaction time as seen in Figures 4 and 5.

The half-life period of 2 is extremely short, i.e., $c a .10$ and $3 \mathrm{~min}$ at 110 and $130^{\circ} \mathrm{C}$ respectively, whereas that of 5 is 600 and $75 \mathrm{~min}$ at 110 and $130^{\circ} \mathrm{C}$ respectively. ${ }^{15}$ Therefore, a primary radical termination giving a dormant species 10 may frequently occur during the polymerization with 2 at such temperatures. It is favorable that the rate of $\mathrm{HM}$ polymer production $\left(R_{\mathrm{p}, 2}\right)$ is nearly the same as that of the polymerization of MMOA with $\mathbf{5}$, i.e., $R_{\mathrm{p}, 2}=R_{\mathrm{p}, 5}$ at 110 and $130^{\circ} \mathrm{C}$ in the initial stage of the polymerization. Thus, it is possible to estimate briefly the rate constant of activation $\left(k_{\text {act }}\right)$ of the dormant by assuming the conventional radical polymerizations of MMOA with 2 and 5 and also $2 \mathrm{k}_{\mathrm{act}, 10}$ [dormant] $=k_{\mathrm{d}, \mathbf{5}}[\mathbf{5}]$ as speculated from $R_{\mathrm{p}, 2}=R_{\mathrm{p}, 5}$. The rate constant of the decomposition of 5 at 110 and $130^{\circ} \mathrm{C}$ has been reported to be $1.9 \times 10^{-5}$ and $1.5 \times 10^{-4} \mathrm{~s}^{-1}$ respectively. ${ }^{15} k_{\text {act }, 10}$ was roughly calculated to be $9.5 \times 10^{-5}$ and $4.3 \times 10^{-4}$ $\mathrm{s}^{-1}$ at 110 and $130^{\circ} \mathrm{C}$ respectively. These are larger than the value of $8\left(k_{\text {act }, 8}=5.0 \times 10^{-5} \mathrm{~s}^{-1} \text { at } 130^{\circ} \mathrm{C}\right)^{12}$ as expected from the decreasing bond dissociation energy due to the generation of both persistent radicals by homoly- 


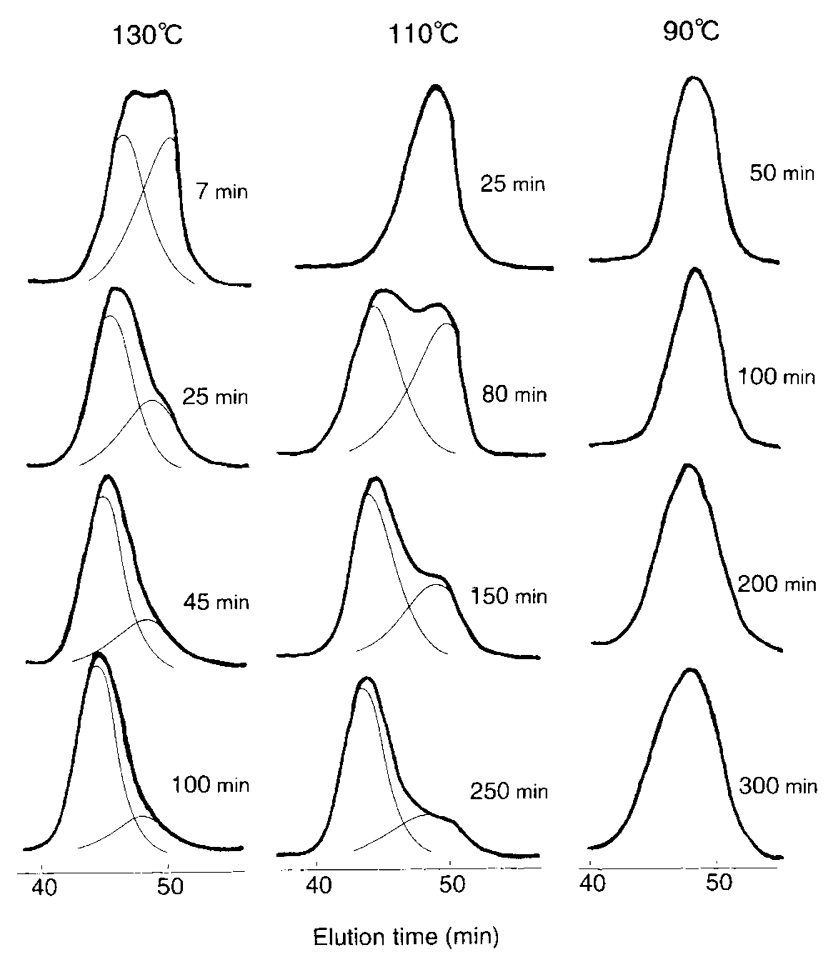

Figure 3. Variation of SEC curves with reaction time during the polymerization of MMOA at 130,110 , and $90^{\circ} \mathrm{C} .[2]=5.0 \times 10^{-3} \mathrm{~mol}$ $\mathrm{L}^{-1}$.

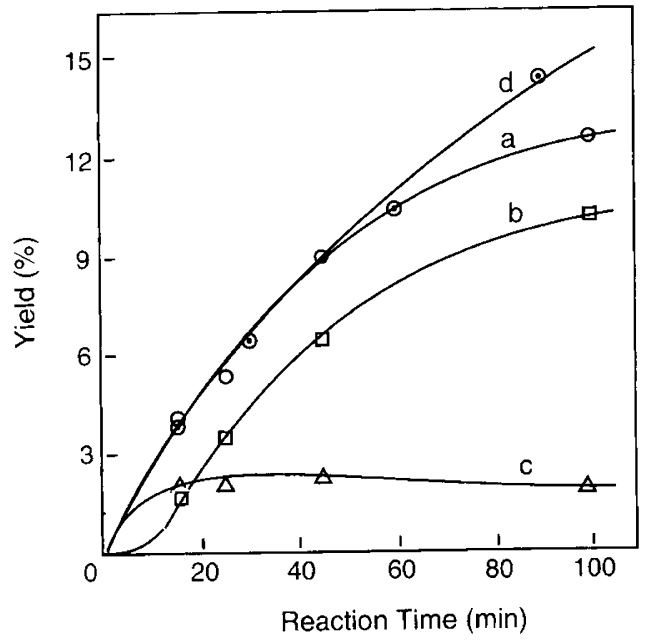

Figure 4. Variation of polymer yield with reaction time in the polymerization of MMOA with $2(a, b, c)$ and $5(d)$ at $130^{\circ} \mathrm{C}$. Yields of total polymer (a and d), higher molecular weight polymer (b) and lower molecular weight polymer (c). $[\mathbf{2}]=[\mathbf{5}]=5.0 \times 10^{-3} \mathrm{~mol} \mathrm{~L}^{-1}$.

sis, ${ }^{17}$ but smaller than that of $6\left(k_{\text {act }, 6}=1.0 \times 10^{3} \mathrm{~s}^{-1}\right.$ at $\left.120^{\circ} \mathrm{C}\right)^{18}$ in Scheme 2 . Therefore, the rate constant of the activation seems to increase in the order of $8<\mathbf{1 0}<\mathbf{6}$ in Scheme 2.

The rate of the homolysis varies generally with the stability of the radicals formed, steric compression, and polar factors. The order of $\mathbf{8}<\mathbf{1 0}<\mathbf{6}$ is in accordance with increasing stability of the polymer radicals and fragment radicals produced, i.e., $9<\mathbf{1 1}$ and $\mathbf{3}<\mathbf{7}$. That is, the higher the stability of the radicals formed, and hence the lower the reaction heat of the homolysis, the more smoothly the homolysis proceeds, as expected from the

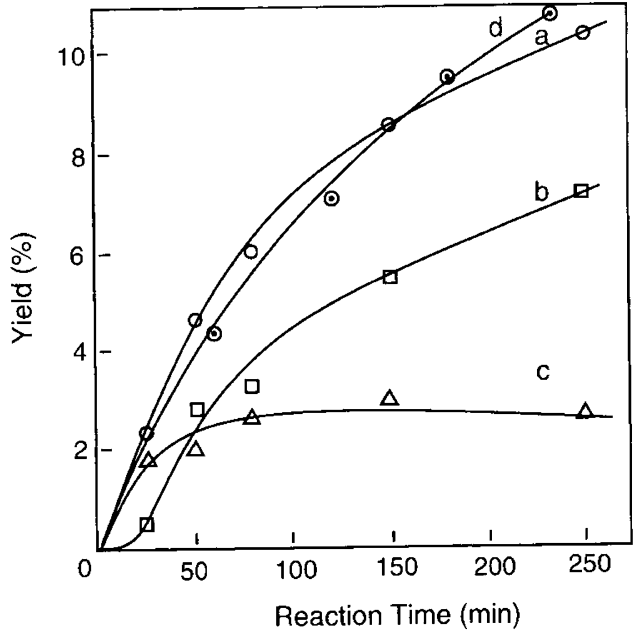

Figure 5. Variation of polymer yield with reaction time in the polymerization of MMOA with $2(\mathrm{a}, \mathrm{b}, \mathrm{c})$ and $\mathbf{5}(\mathrm{d})$ at $110^{\circ} \mathrm{C}$. Yields of total polymer (a and d), higher molecular weight polymer (b) and lower molecular weight polymer $(\mathrm{c}) .[\mathbf{2}]=[\mathbf{5}]=5.0 \times 10^{-3} \mathrm{~mol} \mathrm{~L}^{-1}$.

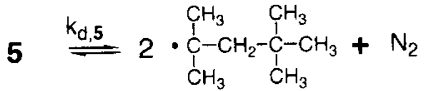
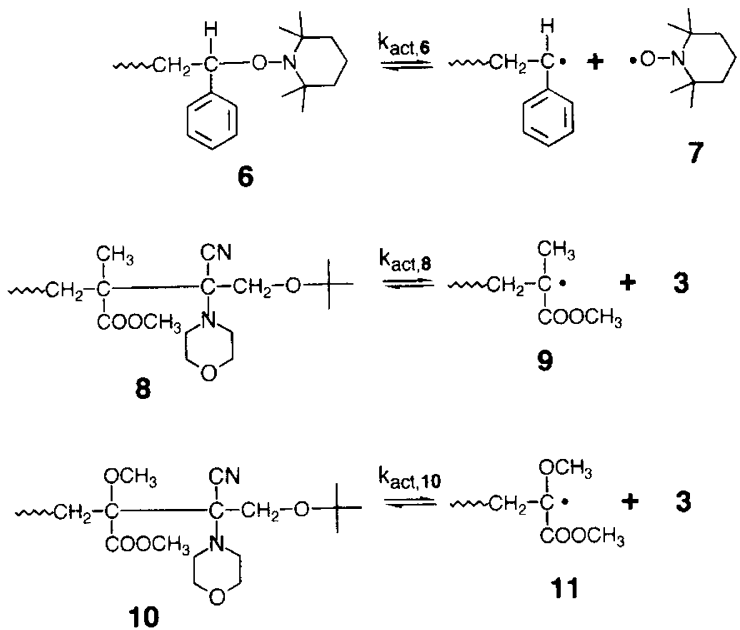

Scheme 2.

extrapolation of the conventional homolysis of organic compounds and the Evans-Polanyi principle although other factors including a steric compression in the homolysis and initiation ability of the dissociated polymer radicals in the polymerization should be considered.

\section{CONCLUSION}

In the present study, cd ethane $\mathbf{2}$ provided a dormant species 10, and 10 dissociated and again initiated the polymerization of MMOA at moderate temperature, in contrast to the polymerization with azo initiator. The rate constant of the activation of 3-capped poly(MMOA) dormant $\mathbf{1 0}$ is larger than that of 3-capped poly(MMA) dormant 8 , but smaller than that of nitroxide $(>1.0 \times$ $\left.10^{-3}\right)^{18}$ - and halogen $(>0.045)^{19}$-capped polystyrene dormants. 


\section{REFERENCES AND NOTES}

1. M. K. Georges, R. P. N. Veregin, P. M. Kazmaier, and G. K. Hamer, Trends Polym. Sci., 2, 66 (1993).

2. G. Moad and E. Rizzardo, Macromolecules, 28, 8722 (1995).

3. C. J. Hawker, J. Am. Chem. Soc., 116, 11185 (1994).

4. M. Kato, M. Kamigaito, M. Sawamoto, and T. Higashimura, Macromolecules, 28, 1721 (1995).

5. D. Greszta, D. Mardare, and K. Matyjaszewski, Macromolecules, 27, 638 (1994).

6. B. B. Wayland, G. Poszmik, S. L. Mukerjee, and M. J. Fryd, J. Am. Chem. Soc., 116, 7943 (1994).

7. T. S. Kwon, S. Kondo, H. Kunisada, and Y. Yuki, Polym. J., 30, 559 (1998).

8. J. Chiefari, Y. K. B. Chong, F. Ercole, J. Krstina, J. Jeffery, T. P. T. Le, R. T. A. Mayadunne, G. F. Meijs, C. L. Moad, G. Moad, E. Rizzardo, and S. H. Thang, Macromolecules, 31, 5559 (1998).

9. T. Otsu and M. Yoshida, Makromol. Chem., Rapid Commun., 3, 127 (1982).
10. H. Tanaka, Trends Polym. Sci., 1, 361 (1993); ibid., 4, 106 (1996).

11. H. Tanaka, Y. Teraoka, T. Sato, and T. Ota, Makromol. Chem., 194, 2719 (1993).

12. H. Tanaka, Y. Tezuka, and K. Fujita, Polym. J., in contribution.

13. S. C. Temin, J. Org. Chem., 22, 1714 (1957)

14. N. Ogata, S. Nosakura, and S. Murahashi, Bull. Chem. Soc. Jpn., 43, 2987 (1970).

15. J. Brandrup and E. H. Immergut, "Polymer Handbook", 3rd ed., John Wiley \& Sons, New York N. Y., 1989 ; “Azo Polymerization Initiators" reported in 1989 by Wako Pure Chem. Ind. Ltd.

16. H. Tanaka and S. Yoshida, Macromolecules, 28, 8117 (1995)

17. H. Tanaka, I. Sakai, and T. Ota, J. Am. Chem. Soc., 108, 2208 (1986) ; H. Tanaka, Y. Yasuda, and T. Ota, J. Chem. Soc., Chem. Commun., 109 (1986).

18. A. Goto and T. Fukuda, Macromolecules, 30, 5183 (1997).

19. K. Ohno, A. Goto, T. Fukuda, J. Xia, and K. Matyjaszewski, Macromolecules, 31, 2699 (1998). 